\title{
Contribuições de Deleuze e Guattari para uma perspectiva rizomática das organizações
}

\author{
ELINE GOMES DE OLIVEIRA ZIOLI ${ }^{12}$ \\ ELISA YOSHIE ICHIKAWA ${ }^{2}$ \\ LUCIANO MENDES ${ }^{3}$
}

\author{
${ }^{1}$ Instituto federal de Educação, Ciência e TeCnologia de São Paulo (IFSP), Campus Boituva, Boituva - SP, Brasil \\ 2 Universidade Estadual de Maringá (UEM) / Programa de Pós-GraduaÇÃo em AdMINISTRação, Maringá - PR, BRASIL \\ ${ }^{3}$ Universidade de SÃo Paulo (USP) / Escola Superior de Agricultura “Luiz de QueIroz", Programa de Pós-Graduação em Administração, \\ PIRACICABA - SP, BRASIL
}

\section{Resumo}

Este ensaio teórico teve como objetivo apresentar a organização a partir de uma perspectiva rizomática de estudo, fazendo uso das concepções teóricas propostas por Deleuze e Guattari, como forma de expandir as possibilidades de estudo das organizações. Uma perspectiva rizomática destaca uma multiplicidade de formas de pensar a organização, expressando e não negando a potência que a constitui. Essa proposta busca dar continuidade aos esforços teóricos que se propõem a superar a construção da teorização organizacional marcada pelo funcionalismo, característico da organização moderna e que dificulta a proliferação de novas perspectivas de estudo. Portanto, a organização entendida a partir de uma perspectiva rizomática segue um devir organização-rizoma, composto por linhas que em alguns momentos se apresentam como de segmentaridade (organização, classificação). Em outros momentos essas linhas se rompem em linhas de fuga (de transformação da multiplicidade). Ao final, compreendemos que a organização rizomática se apresenta como uma forma subversiva da organização.

Palavras-chave: Teoria das Organizações. Deleuze e Guattari. Multiplicidade. Organização rizomática.

\section{Deleuze and Guattari's contributions to a rhizomatic perspective of organizations}

\begin{abstract}
This theoretical essay presents the organization from a rhizomatic perspective of study, using the theoretical conceptions proposed by Deleuze and Guattari to expand the possibilities of organization studies. A rhizomatic perspective highlights a multiplicity of ways of thinking about the organization, expressing and not denying the power that constitutes it. This essay seeks to continue the theoretical efforts proposed to overcome the construction of organizational theory marked by functionalism, a characteristic of a modern organization that hinders the proliferation of new study perspectives. Therefore, the rhizomatic perspective on organizations follows an organization-rhizome becoming, composed of lines that may appear as segmentation (organization, classification), or appear as lines breaking into lines of flight (of a transformation of multiplicity). Therefore, the rhizomatic organization presents itself as a subversive form of the organization.
\end{abstract}

Keywords: Organization Theory. Deleuze and Guattari. Multiplicity. Rhizomatic Organization.

\section{Contribuciones de Deleuze y Guattari a una perspectiva rizomática de las organizaciones}

\section{Resumen}

Este artículo tuvo como objetivo presentar la organización desde una perspectiva de estudio rizomática, haciendo uso de las concepciones teóricas propuestas por Deleuze y Guattari, como una forma de ampliar las posibilidades de estudio de las organizaciones. Una perspectiva rizomática resalta una multiplicidad de formas de pensar acerca de la organización, expresando y sin negar el poder que la constituye. Esta propuesta busca dar continuidad a los esfuerzos teóricos que se proponen superar la construcción de la teorización organizacional marcada por el funcionalismo, característico de la organización moderna y que dificulta la proliferación de nuevas perspectivas de estudio. Por lo tanto, la organización entendida desde una perspectiva rizomática sigue un devenir organización-rizoma, compuesto de líneas que a veces aparecen como segmentación (organización, clasificación). En otras ocasiones, estas líneas se dividen en líneas de fuga (de transformación de la multiplicidad). Finalmente, entendemos que la organización rizomática se presenta como una forma subversiva de la organización.

Palabras clave: Teoría de la organización. Deleuze y Guattari. Multiplicidad. Organización rizomática. 


\section{INTRODUÇÃO}

Organizar é uma prática essencialmente humana, o que na descrição de Clegg, Kornberger e Rhodes (2005) é o reflexo de um mundo complexamente caótico, em que o organizar é a ação de reduzir a complexidade do real. Nesse sentido, as análises convencionais das organizações têm-se concentrado em uma perspectiva de organização como meio de ordenar, estruturar e controlar o mundo. Independente se formal ou informal, a organização é imposta como oficial, detentora e instituidora da verdade e da ordem moral (Cooper \& Burrell, 1988).

A compreensão que sempre predominou nas teorias organizacionais foi da organização formal-funcional, capaz de impulsionar uma condição racional-instrumental aos membros que a integram. Essa forma de compreender a organização gerava um limite espacial/ambiental que a distinguia de outras organizações ou de outros espaços e ambientes (Cooper, 1990). Foram essas concepções e compreensões sobre a organização que passaram a ser desconstruídas ou questionadas nos últimos anos. Não tardou para que esse limite da organização fosse questionado (Cooper, 1990), assim como os aspectos racionais (Brunsson, 1982) e formais-funcionais das organizações (Alvesson \& Deetz, 2006).

Não por acaso esses estudos têm expandido as compreensões sobre as organizações, deixando evidente que o conceito de organização não pode ser limitado ao sentido de ordenamento do real, sendo que na organização, a ordem e a desordem são interdependentes, suplementares e parasitárias (Clegg, Kornberger \& Rhodes, 2005). É nesta linha que Reedy (2014) destaca a necessidade de superar a conceituação funcionalista de organização formal, abrindo o campo de estudo das organizações para novas perspectivas, teorizando e estudando as organizações como produto de um contexto social.

Em uma busca por expandir as análises organizacionais, a produção científica na área da administração tem se aproximado das contribuições de Deleuze e Guattari. Assim, os trabalhos de Grisci (2008), Cavalcanti e Alcadipani (2011), Cavalcanti (2016) e Barreto, Carrieri e Romagnoli (2020) destacam a possibilidade de os estudos organizacionais brasileiros expandirem suas análises por meio da teorização de Deleuze e Guattari. Contudo, essas contribuições, mesmo questionando os fundamentos que regem a teorização organizacional clássica, não avançam teoricamente em uma proposição conceitual alternativa à organização formal.

Nesse sentido, construímos esse ensaio partindo da contribuição teórica de Deleuze e Guattari e propomos uma forma rizomática de compreender a organização, que deve ser percebida como movimento, não aceitando os formalismos impostos. Assim, a organização rizomática é o espaço de múltiplos movimentos, uma abertura para a potência e toda possibilidade de criação que ela representa. Mesmo fugindo ao sentido tradicional de organização como contrário de desordem, ela não nega sua arborescência (aspecto formal), mas reforça a existência de movimentos de indisciplina, que lutam para não serem organizados e que encontram no desejo o combustível para suas criações.

Iniciamos essa discussão a partir da teorização tradicional dos estudos organizacionais, da construção do conceito de organização e seu desenvolvimento e da abertura que os estudiosos têm realizado no campo, buscando expandir a compreensão de organizações. Em seguida, discutimos o corpo conceitual da teoria de Deleuze e Guattari de modo a compreender a questão da univocidade do ser, central para os autores. Por último, apresentamos a perspectiva rizomática aplicada ao estudo das organizações, o que permite entender a organização como rizoma, promovendo uma abertura do conceito para um campo de multiplicidades antes fechado por estruturas arborescentes da organização formal.

\section{O PANORAMA GERAL DAS DISCUSSÕES SOBRE ORGANIZAÇÕES}

\section{Sobre a teorização organizacional}

O ato de organizar é apresentado como uma ação tipicamente humana, necessária, como destaca Chia (1999), para tornar o mundo habitável. Entretanto, salientam Alcadipani e Rosa (2011), a sistematização de uma teoria das organizações é algo recente, ligada às mudanças tecnológicas e sociais que ocorreram na segunda metade do século XIX. Nesse contexto, Reed (2010, p. 64) apresenta a teoria das organizações como "um campo de conflitos históricos em que diferentes línguas, abordagens e filosofias lutam por reconhecimento e aceitação". O autor defende que uma teoria não pode ser analisada fora do contexto social e histórico em que essa foi criada e recriada com o objetivo de perturbar convenções ortodoxas. 
Por esse motivo, para Morgan (1990) o estudo das organizações exige novos modos de conceituação teórica, utilização de diferentes ferramentas e técnicas de pesquisas, além de novos critérios para determinar a legitimidade e qualidade dos conhecimentos gerados. A proposta do autor de uma diversidade de paradigmas representa uma abertura para novos problemas e questões que devem ser abordados pelos estudos organizacionais, sendo um desafio para a legitimidade do que já se sabe sobre as organizações.

A discussão dos paradigmas sociais, realizada por Burrell e Morgan (1979), trata da constituição do campo da teorização organizacional. Segundo Caldas (2005), o argumento defendido pelos autores é da prisão e limitação exercida pelo paradigma funcionalista na compreensão das organizações. Esse paradigma está limitado e centrado na busca pela eficiência, enfatizando a especialização e a autoridade, que são características da organização moderna, em detrimento da diferenciação (Cooper, 1990; Cooper \& Burrell, 1988). No paradigma funcionalista, as organizações são vistas como um meio de ordenar, estruturar e controlar o mundo caótico (Clegg, Kornberger \& Rhodes, 2005). É dessa concepção de organização que surgiu o termo organização formal (Ahrne \& Brunsson, 2011).

Segundo Cooper e Burrell (1988), o termo organização formal se refere não apenas ao que é adequado ou metódico, mas também oficial e colocado como uma verdade, assumindo um papel de ordem moral. Compreender a organização como formal é seguir a lógica da sociedade moderna (Reed, 2010), que tem a organização industrial como fonte de unidade e progresso, onde o sujeito racional é constituído pelo sistema de funcionalidade social (Cooper \& Burrell, 1988). A perspectiva de organização moderna, segundo Power (1990), compreende indivíduos que se percebem como entidades funcionais das organizações, com o propósito de alcançar maior status, validando desse modo uma abordagem funcionalista para as organizações.

Desenvolvendo-se na forma de oposição ao modelo modernista de organização, as abordagens pós-modernistas são, segundo Cooper e Burrell (1988), um olhar para a diferença, fugindo do determinismo da organização formal. Nesse sentido, Power (1990) ressalta o entendimento de organização como uma instabilidade potencial, permeável e não fechada, em que a análise se volta para seus limites ou superfícies. Para o autor a teoria organizacional pós-modernista exige do pesquisador sensibilidade para observar a diversidade e fluidez da vida organizacional, onde modelos prontos e únicos não são suficientes para orientar a pesquisa.

Para Cooper e Burrell (1988) a organização formal tem como principal característica o desejo de anular seu oposto. Nesse sentido, as análises convencionais buscam criar um senso de ordem evidenciado pela figura da organização (Clegg, Kornberger \& Rhodes, 2005). Ahrne e Brunsson (2011) destacam a necessidade de os estudos buscarem uma definição de organização mais ampla, sem equivalência com a organização formal, o que torna os estudos organizacionais mais relevantes, ao abordar questões mais amplas das ciências sociais. Desse modo, Segnini e Alcadipani (2014) colocam que as discussões têm se direcionado para um entendimento da organização como um fenômeno que envolve fenômenos humanos, históricos e sociais.

Seguindo as considerações de Cooper e Burrell (1988), Cooper (1990), Morgan (1990), Power (1990), Ahrne e Brunsson (2011) e Segnini e Alcadipani (2014), fica evidente a necessidade de ampliar a compreensão sobre a organização, com definições mais amplas e que transcendem a lógica da organização formal, capaz de instituir a instabilidade, a desconstrução dos limites organizacionais e o rompimento com a perspectiva funcionalista da organização. Para tanto, é necessário expandir o conceito de organização.

\section{Expandindo conceitualmente organizações}

Reedy (2014) coloca que a solução para compreender as organizações como fenômeno, não ocorrerá ao analisar locais alternativos da organização utilizando categorias convencionais de análise: é necessário expandir os estudos para além das estruturas teóricas usuais. Esse autor coloca que os estudos organizacionais necessitam de uma estrutura teórica que se distancie da teorização convencional, para abordar os tipos de organizações alternativas (esquecidas e excluídas pelas teorias convencionais). Reedy (2014) destaca que as contribuições pós-estruturalistas têm trabalhado em uma reformulação da base da teorização organizacional. De acordo com Peters (2000) e Souza (2012) o pós-estruturalismo francês representa uma transformação no campo do conhecimento e que é uma das correntes de estudos que integram o movimento pós-moderno.

A fim de expandir as discussões relacionadas aos estudos organizacionais, é preciso voltar-se para as contribuições situadas em uma perspectiva pós-estruturalista, tendo em vista o aspecto inovador e original do pós-estruturalismo, no que se refere ao desenvolvimento de diferentes formas de análise (Peters, 2000). Na descrição de Clegg, Kornberger e Rhodes (2005), 
a teoria organizacional pós-estruturalista é instrutiva ao analisar de que forma os desejos se manifestam na prática, por meio da observação do funcionamento das micropráticas de organização primária. Para os autores, compreender as organizações é olhar para o caos, o barulho, o paradoxo, a diferença, é compreender que existe uma dinâmica, um som, que não apenas reduz a complexidade, mas que produz essa complexidade em um movimento incessante. Desse modo, trabalhar com o conceito de organização não é negar a existência da desorganização, ou que a organização anula a desordem, é preciso compreender, como foi destacado por Clegg, Kornberger e Rhodes (2005), o aspecto dependente, suplementar e parasitário da ordem e da desordem (organização e desorganização).

Assim, Munro (2001) destaca que a organização pode ser compreendida ao se investigar a desordem, uma vez que, a desorganização é, para Clegg, Kornberger e Rhodes (2005), pré-condição para que ocorra a organização. Tomar a organização a partir do que a compõe é reproduzir um olhar funcionalista da organização, devendo o pesquisador que busca expandir o conceito observar o que é excluído desse sistema (Munro, 2001). De acordo com a abordagem de Cooper (1990), uma concepção alternativa para compreender a organização a coloca como uma estrutura diferencial, ligada a uma desorganização que apenas pode ser organizada por uma força externa e pelo exercício violento de poder, que é denominado pelo autor como Grau Zero da Organização. Grau zero é um estado de nenhuma ordem, organização ou direção específica, ou seja, é um processo de indecidibilidade que perpassa toda organização social (Cooper, 1990).

Como colocam Linstead e Thanem (2007), o grau zero de organização não é ele próprio organizado, mas compreende a potencialidade de ser organização e não organização. Discussões que buscam questionar o status ontológico das organizações foram desenvolvidas utilizando proposições teóricas de disciplinas como a filosofia, sociologia, antropologia e psicanálise. Essa negação de limites e de pacotes prontos para compreender as organizações é o ponto de partida para a discussão que nos propomos realizar nesse ensaio. Para isso, apresentamos no próximo tópico as contribuições teóricas de Deleuze e Guattari, abordando seus principais conceitos e permitindo assim uma visão geral da teoria da multiplicidade desses autores.

\section{O ENCONTRO ENTRE A FILOSOFIA DE GILES DELEUZE E A PSICANÁLISE DE FÉLIX GUATTARI}

Individualmente Deleuze e Guattari desenvolveram conceitos próprios, enquanto Deleuze trabalhava nos conceitos de diferença, repetição e sujeito, Guattari desenvolvia a concepção de máquinas desejantes (Deleuze, 2008). O encontro e produção conjunta de Deleuze e Guattari é, segundo Dosse (2010, p. 13), um dilema, uma produção intelectual comum, desenvolvida entre 1969 e 1991 entre sujeitos "de sensibilidades tão diferentes e estilos tão contrastantes". Gilles Deleuze já era um filósofo reconhecido, Félix Guattari, por sua vez, era militante político e administrador da clínica psiquiátrica de La Borde, e se deslocava pelo campo da psicanálise e das ciências sociais.

Cavalcanti (2016) destaca a dificuldade em compreender a obra filosófica de Deleuze a partir de conceitos específicos, exigindo um olhar para a totalidade da sua obra. Quanto à produção conjunta, Dosse (2010) salienta que não se pode buscar definir uma paternidade dos conceitos produzidos pelos autores, o que desprezaria o agenciamento coletivo de enunciação estabelecido nessa produção. Desse modo, nossa proposta é apresentar o quadro geral dos conceitos, pontuando os encontros e avanços promovidos pelos autores.

\section{A produção da subjetividade, o inconsciente maquínico e a univocidade do ser}

A questão da univocidade do ser é a base da formulação do pensamento teórico de Deleuze, suas construções e apropriações conceituais giram em torno da afirmação da univocidade (Machado, 2009). Por sua vez, os estudos desenvolvidos por Guattari (2006) levavam à compreensão de uma subjetividade plural, produzida em instâncias individuais, coletivas e institucionais, promovendo a ampliação do entendimento de inconsciente. Para Guattari (2006), estudar o inconsciente é abri-lo para a existência de fatores subjetivos na atualidade histórica, nas produções maquínicas de subjetividade e dos aspectos etológicos e ecológicos relacionados à subjetividade humana. A questão da subjetividade vinha sendo discutida por Deleuze (1974, 2018), contudo o encontro com o conceito de máquinas desejantes que estava sendo trabalhado por Guattari $(1985,2006)$ contribui para a construção do entendimento de um inconsciente maquínico. Como destaca Dosse (2010), Deleuze encontra no conceito de máquinas de Guattari uma possibilidade de sair do pensamento estrutural. 
O termo máquina refere-se ao estado de sujeito não humano, que não pode ser compreendido apenas por sua materialidade, devendo seguir por outros elementos que compõem as dimensões maquínicas de subjetivação (Guattari, 2006; Guattari \& Rolnik, 1996). Nesse sentido, os sujeitos funcionam como máquinas, segundo Deleuze e Guattari (2004) tendo o desejo como motor que faz andar o processo de produção das subjetivações. Como máquinas desejantes, segundo Lawley (2005), os corpos sofrem por serem organizados e estarem em constante processo de produção, surgindo uma tensão entre o desejo e sua organização.

O inconsciente maquínico, para Guattari (1985), assemelha-se ao inconsciente freudiano, pois não conhece a negação (do consciente), o que permite, por exemplo, ser ao mesmo tempo Eu e Outro, não como entidades polarizadas, mas como processos maquínicos, denominados como devir. O devir é o inconsciente maquínico que nos faz transitar por platôs de intensidade constituídos por esses devires. Desse modo, o inconsciente não é uma instância secreta do sujeito dependendo unicamente dele próprio, mas sim um emaranhado de interações maquínicas, em que somos articulados a todos os sistemas de potência e formações de poder que nos cercam (Guattari, 1985).

Nesse sentido, a subjetividade não é apenas fabricada no inconsciente, nas fases psicogenéticas da psicanálise, mas também "nas grandes máquinas sociais, mass-mediáticas, linguísticas, que não podem ser qualificadas de humanas" (Guattari, 2006, p. 20). Sendo, desse modo, como destacam Guattari e Rolnik (1996), uma subjetividade de natureza industrial (maquínica), fabricada, modelada, recebida, consumida, olhando desse modo para uma parte não humana, pré-pessoal da subjetividade (Guattari, 2006). Para Deleuze (2013), a chave para compreender a subjetivação está na dimensão do pensamento, o que já vinha sendo discutido pelo autor em sua tese "Diferença e Repetição", ao propor um pensamento sem imagem em oposição ao pensamento de imagem dogmática da filosofia tradicional, que aprisiona a diferença.

Deleuze (2018) salienta que a imagem do pensamento trata de uma compreensão pré-filosófica e natural do que é pensar, que possui e busca o verdadeiro. Nesse sentido, a diferença apenas pode ser pensada como o idêntico, semelhante, análogo, oposto, "sempre em relação a uma identidade concebida" é que a diferença "se torna objeto da representação", alienando a diferença e a repetição nas generalidades da representação (Deleuze, 2018, p. 190). Nesse sentido, o autor enfatiza a univocidade do ser não como o uno compreendido em um único sentido, o que levaria a uma homogeneização da diferença. Mas o ser como uno é, para Deleuze $(2018$, p. 68), o dizer em um único sentido de todas as suas diferenças individuantes (os entes ou modalidades intrínsecas), sendo que "o Ser é o mesmo para todas estas modalidades, mas estas modalidades não são as mesmas".

São retomados por Deleuze (2018) três momentos da história da filosofia moderna para elaboração do seu entendimento da univocidade do ser. Primeiro em Duns Scot, em sua ontologia pura, que pensa o ser unívoco enquanto neutro/indiferente. Segundo, em Espinosa, que faz do ser unívoco objeto de afirmação, expressivo (proposição expressiva afirmativa). E terceiro em Nietzsche com o sentido de eterno retorno, que seria o ser comum de todas as diferenças, ou a própria univocidade em que "o Ser se diz num mesmo sentido, mas esse sentido é o do eterno retorno, como retorno ou repetição daquilo de que ele se diz" (Deleuze, 2018, p. 69).

Como destaca Spinks (2010) o uso do eterno retorno por Deleuze é um destaque para a existência das diferenças que constituem os sujeitos e as coisas. A diferença para Deleuze $(2013,2018)$ é como um tratamento afirmativo das singularidades, enfatizando dessa forma o pluralismo dessas diferenças, livres, selvagens, não domadas, que persiste frente às simplificações dos limites e oposições (Deleuze, 2018). Assim, a compreensão de um inconsciente maquínico é o desenho dessas diferenças selvagens do autor, que não precisa ser justificado por uma imagem dogmática do que é a verdade, pois é o pensamento sem imagem que é a própria gênese do ato de pensar.

Olhar para a diferença significa compreender a natureza do mundo como ela é concebida, dado que cada aspecto da realidade demonstra a diferença que não precisa se fundamentar em nenhum outro aspecto, pois se refere às particularidades e singularidades de cada indivíduo, momento, objeto e percepção (Deleuze, 2018; Stagoll, 2010). Quando Deleuze (2018) trata da essência da diferença e sua capacidade de representar a potência, fica evidente a impossibilidade da generalidade, uma vez que, a diferença que constitui essas subjetividades maquínicas (Guattari, 2006; Guattari \& Rolnik, 1996) compõe um pensamento sem imagem, pensamento nascido do pensamento e não da representação (Deleuze, 2018). Assim, a repetição destaca a existência de uma singularidade que não pode ser trocada ou substituída (Deleuze, 2018), que se metamorfoseia a todo instante, encontrando novos caminhos, seguindo os fluxos, tendo o desejo como combustível para suas produções. 
Nesse sentido, repetir, para Deleuze (2018), é um comportamento em relação a algo que é único ou singular em cada sujeito, sem semelhante ou equivalente, que pode ser a expressão de algo secreto, uma repetição interior e mais profunda na singularidade que a abriga. Ao invés de uma generalidade do particular, é uma universalidade do singular, como uma transgressão, a "singularidade contra o geral", com o propósito de denunciar o caráter nominal e geral da lei defendendo uma "realidade mais profunda e mais artística" pautada nas singularidades do sujeito, ou o que o torna diferente (Deleuze, 2018, p. 18).

\section{A dobra, ligando o pensar e o ser}

O pensamento é, para Deleuze $(2013,2008)$, uma das dimensões que compõe as subjetividades (poder, saber e pensamento) e é uma dimensão externa ao sujeito, ou seja, aquilo que vem do lado de fora e permanece no lado de fora. Mas o pensamento surge, ao mesmo tempo, do lado de dentro, como o que não pensa e não pode pensar, o impensado. $O$ que não condiz com o entendimento filosófico do pensamento como exercício natural, que se volta para o verdadeiro seguindo uma "natureza reta do pensamento" (Deleuze, 2018, p. 181). Para o autor, o pensamento vem do intensivo, da sensibilidade que leva ao que existe para ser pensando ou aquilo que ainda não é pensado, o que compõe o pensamento sem imagem.

Dessa forma, as ideias para Deleuze (2018) são multiplicidades que se referem ao diferencial presente no pensamento. Nesse ponto da reflexão do autor, pode-se identificar a base da proposição do conceito de rizoma (Deleuze \& Guattari, 2017a) como a experimentação dessas multiplicidades que Deleuze (2018) relaciona à produção do pensamento. Se o pensamento sem imagem é a libertação da diferença, essa liberdade se dá por meio do aprendizado, que diferente do saber (figura empírica de resultados e experiências) o aprender é a estrutura transcendental do pensamento, ou seja, o que ainda não foi pensado.

Para Deleuze (2013) o impensado corresponde a um lado de fora (externo ao sujeito), que não possui forma, um espaço de ação das forças, abertas para uma multiplicidade de possíveis relações. Assim, o processo de produção de um pensamento sem imagem critica o entendimento típico de subjetividade, como interioridade e exterioridade simples (O'Sullivan, 2010). Desse modo, Deleuze (2013) demonstra, por meio do conceito de dobra, a dinâmica que constitui o pensamento como um processo em constante estado de transformação. Para o autor, a dobra é a reduplicação do outro, do diferente que constitui o lado de fora. Essa reduplicação (do externo - lado de fora) não é uma representação do eu, mas é a própria presença do outro em mim.

Nesse sentido, a subjetivação maquínica de Guattari (2006) é realizada pela dobra que, segundo Deleuze (2013, p. 112), apresenta quatro modalidades: primeiro referente à parte material de nós mesmos, aqui representada pelo desejo; a segunda trata das relações de forças; a terceira é a dobra do saber e liga a verdade com o ser e o ser com a verdade; e a quarta dobra é o próprio lado de fora, "é dela que o sujeito espera, de diversos modos, a imortalidade, ou a eternidade, a salvação, a liberdade, a morte, o desprendimento". Pick (2017) destaca que o conceito de dobra nos remete à interação entre forma e força, representando um ponto de inflexão onde a variação ocorre.

A forma para Deleuze (2013) são as exterioridades representadas pelos estratos (formações históricas) e que representam o domínio do saber, determinado pelo ver e falar (o visível e o enunciável). Nesse ponto, o autor destaca a diferença entre exterioridades, que se refere a formas (ver e falar) e o lado de fora. Para Deleuze (2013, p. 126) "pensar é dobrar, é duplicar o fora com um dentro que lhe é coextensivo", o dentro passa a existir quando é definido um limite ou a dobra do lado do fora. Quando o fora se dobra ele cria um dentro (Badiou, 1997). Nesse sentido, Deleuze (2013) compreende a dobra como uma memória ou a memória do lado de fora, que por sua vez é uma abertura para o futuro, que vive em constante metamorfose. Conforme apresenta Badiou (1997) a dobra pode ser entendida como a criação de um si (um sujeito) partindo da compreensão de que esse sujeito resulta de uma operação do lado de fora, não sendo autônomo ou espontâneo. Nesse sentido, o pensamento é co-participante ontológico da potência do Uno, sendo dessa forma a dobra do Ser (Badiou, 1997), assim, o Uno é para Deleuze (2018) uma multiplicidade. 


\section{O Rizoma como espaço das multiplicidades}

Rizoma é um termo que Deleuze e Guattari (2017a) emprestam da botânica e representa as raízes secundárias, que ao saírem da raiz principal criam uma multiplicidade de caminhos ou pontos, alterando o aspecto inicial da raiz secundária, não sendo mais uma raiz única (ligação de um ponto a outro), mas uma raiz que se liga e dá origem a tantas outras, que se transformam, ou dão lugar a outras raízes. O rizoma representa a experimentação dessas multiplicidades. Colebrook (2002) destaca que o termo rizoma para Deleuze e Guattari representa aquilo que é aleatório, proliferante, com conexões descentralizadas, diferente do termo arborescente, que segue uma ordem e direção distinta.

O rizoma representa, para a construção teórica de Deleuze e Guattari, uma forma de mapear um processo, não criando hierarquias, mas considerando o pensamento em rede, relacional e transversal, e que não deve ser visto como fixo (Colman, 2010). O rizoma é na descrição de Colman (2010) uma matriz móvel, composta por partes orgânicas e não orgânicas, que formam conexões simbióticas e aparalelas em rotas ainda indeterminadas. Deleuze e Guattari (2017b) tratam o rizoma como uma formação molecular que traça um plano que não possui dimensões, constitui uma multiplicidade que não está subordinada ao uno e é livre em seu movimento de agir no plano da imanência.

Para Deleuze e Guattari (2017a, 2015) o rizoma é composto por linhas de segmentaridade e linhas de fuga, não pontos e posições como os encontrados em uma árvore. Assim, para os autores, as linhas de segmentaridade tratam das estratificações, definições, categorizações e podem ser do tipo flexível (resultam de multiplicidades) ou dura (dependem de grandes máquinas de binarização direta), enquanto que as linhas de fuga representam as rupturas, em que a multiplicidade se metamorfoseia. Desse modo, o rizoma é movimento, rupturas, rompimentos das linhas de segmentaridade pelas linhas de fuga, mas ainda assim essas linhas de fuga podem ser novamente reorganizadas sobre novos arranjos, reconstituindo o sujeito (Deleuze \& Guattari, 2017a).

Deleuze e Guattari (2017b) salientam que tanto o rizoma como o sistema arborescente são constituídos por estratos e agenciamentos. Os estratos são, na descrição de Deleuze (2013, p. 57) "formações históricas, positividades ou empiricidades", formados por coisas e palavras, o que se vê e o que se fala. Já os agenciamentos são arranjos ou processos de organização e montagem, que criam formas de funcionamento ou novos territórios (Livesey, 2010).

Deleuze e Guattari (2017b) observam que os agenciamentos se constituem por meio do desejo, que não possui uma determinação natural ou espontânea, mas é agenciado e está constantemente agenciando. Portanto, para os autores os agenciamentos são todo conjunto de singularidades e traços extraídos do fluxo, que são selecionados, organizados e estratificados, convergindo naturalmente ou artificialmente, se apresentando como uma invenção. Analisar os agenciamentos é analisar o território que o envolve, agenciar é tornar algo seu, como "minha casa", "meu trabalho", "meu amigo". Desse modo, os agenciamentos extraem os fragmentos dos meios e thes confere novo sentido (ritornelo) em um desenvolvimento constante de devires (Deleuze \& Guattari, 2017b, 2017c).

Nesse sentido, Deleuze e Guattari (2017a, p. 38) relacionam o rizoma ao esquema do pensamento que apresentamos no tópico anterior, para os autores "o rizoma é esta produção de inconsciente". As multiplicidades que correm pelo rizoma, retratam as formações das subjetividades, as construções maquínicas do inconsciente, a potência que constitui o pensamento fora do sujeito e que será dobrada compondo uma memória da potência do lado de fora, agindo sobre os estratos, tendo como combustível os desejos e promovendo novos agenciamentos.

Entretanto, Deleuze e Guattari (2017a) destacam que o rizoma pode ser fechado, arborificado, onde o desejo não se movimenta mais e não produz. As forças do lado de fora que agem sobre os estratos por meio da dobra estão endurecidas por poderes significantes e afetos subjetivos. Elas formam, para Rolnik (2018), uma nova dobra, em que a pulsão (desejo) se volta para construção de novos mundos a partir dos desígnios de um regime colonial-capitalístico e não mais por demandas próprias do desejo que busca preservar a vida.

Desse modo, não se deve compreender o rizoma de forma binária, como contrário à arborescência, da mesma forma que a potência constituída no campo da imanência não deve ser vista como algo que apenas cria novos mundos e segue as demandas do desejo para manutenção da vida. Deleuze e Guattari (2017a) reforçam que existem estruturas de árvore ou de raízes nos rizomas, da mesma forma que de um galho de árvore e estrutura raiz pode brotar novamente um rizoma. Não existe uma oposição de modelos (rizomático e arborescente) "existem nós de arborescência nos rizomas, empuxos rizomáticos nas raízes" (Deleuze \& Guattari, 2017a, p. 42). 
Como destacam Deleuze e Guattari (2017a, p. 26) "os grupos e os indivíduos contém microfascismos sempre à espera de cristalização", os rompimentos operados pelas linhas de fuga nos rizomas podem reterritorializar em linhas de segmentaridade dura que classifica e organiza as pulsões do desejo. Nesse sentido, Guattari (1985) destaca que uma máquina desejante também encontra formas de alienação, onde a castração dos desejos faz parte da construção de uma sociedade real.

Para Guattari (1985), apenas uma revolução molecular no sentido de retomada das máquinas técnicas pelas máquinas desejantes é que permitirão atingir o ajustamento entre os desejos e o progresso técnico científico. Deleuze e Guattari (2017a) destacam que o rizoma é a chave para essa retomada operada por meio das subjetividades, criando novos mundos, novas formas de viver, novos inconscientes, enunciados e desejos.

\section{POR QUAIS CAMINHOS UMA PERSPECTIVA RIZOMÁTICA TEM LEVADO E PODE LEVAR AS ORGANIZAÇÕES?}

Estudiosos das organizações têm buscado trilhar diferentes caminhos para o desenvolvimento da teorização organizacional, sendo o caminho que busca um entendimento epistemológico das organizações mais frequentado do que o ontológico (Linstead \& Thanem, 2007). Por essa razão, as discussões ontológicas realizadas por Deleuze e Guattari representam profícuo campo de estudo.

As produções nacionais que se utilizam dos conceitos de Deleuze e Guattari os fazem de diferentes maneiras, entretanto apenas o trabalho de Grisci (2008) realiza um estudo empírico. A autora analisa, a partir do conceito de rizoma, os modos de potencialização do controle, operados pelo paradigma tecnológico e de que forma esse controle age na subjetividade. O estudo foi desenvolvido em uma instituição bancária portuguesa. Nesse trabalho, inédito nas produções acadêmicas na área de administração, a autora trata o controle como rizomático.

Outros trabalhos abordam a perspectiva teórica apenas de Deleuze, como Cavalcanti e Alcadipani (2011), que propõem uma crítica pós-estruturalista, relacionando as discussões de Deleuze com as contribuições de Foucault. Dessa forma, os autores destacam o pragmatismo presente no pensamento teórico de Deleuze e Foucault como forma de esclarecer os mal-entendidos presentes na crítica pós-estruturalista. Em um texto mais recente, Cavalcanti (2016) destaca as possibilidades de intersecção entre a teorização de Deleuze e os estudos organizacionais, deixando evidente a lacuna existente, que pode ser preenchida a partir das reflexões desenvolvidas no contexto da filosofia pós-estruturalista. Para a autora, elementos marginalizados pela produção do conhecimento dominante podem ser investigados utilizando a filosofia deleuziana.

Outro trabalho que utiliza a teoria de Deleuze e Guattari é o de Paes e Borges (2016), que fazem uma crítica à abordagem do sujeito nas organizações, apresentando o termo organização rizomática. Contudo, no desenvolvimento desse ensaio, o termo organização rizomática não será tratado de forma metafórica, como colocado pelos autores, mas como proposta de expansão conceitual da teoria organizacional, a partir do pensamento de Deleuze e Guattari.

Como forma de representar a multiplicidade da teoria deleuze-guattariana, Barreto, Carrieri e Romagnoli (2020) propõem uma dupla apropriação do conceito de rizoma, como postura rizomática do pesquisador e como orientador metodológico. A proposição dos autores se volta para as necessidades identificadas no desenvolvimento de pesquisas empíricas nos estudos organizacionais, promovendo novas formas de pensar as organizações e seu cotidiano.

Para Cavalcanti (2016) o uso isolado de conceitos gera uma compreensão equivocada da obra de Deleuze. Para Sorensen (2005) apesar da aparência de abertura dos estudos organizacionais para a produção teórica de Deleuze e Guattari, essa inserção tem ocorrido dentro dos limites referenciais já definidos pelos teóricos das organizações. Desse modo, ocorre uma desterritorialização da teoria deleuze-guattariana e uma reterritorialização negativa (Sorensen, 2005), com a perda de sentido da teoria elaborada pelos autores. Portanto, uma proposta de avanços na teoria organizacional deve promover uma desterritorialização dos seus territórios ortodoxos, tradicionais, de uma organização formal enquanto oposição a desordem, e ser reterritorializada na multiplicidade contida no pensamento de Deleuze e Guattari (2017a).

Nas produções internacionais, o conceito de rizoma tem sido utilizado como forma de expandir a compreensão teórica de organização, como pode ser observado em: Chia (1999), ao discutir a mudança nas organizações; Lawley (2005), que o apresenta como proposta para criação de ontologias rizomáticas; Ball (2005), que o utiliza em uma análise do controle dos 
corpos nas organizações; Pick (2017), que utiliza em conjunto com o conceito de dobra para discutir avanços na teoria das organizações; e Kuronen e Huhtinen (2017), que utilizam o conceito em uma análise da organização do Estado Islâmico. Os trabalhos citados, mesmo enfatizando o rizoma, o relacionam a outros conceitos da teoria de Deleuze e Guattari, semelhante às propostas de Bougen e Young (2000), Styhre (2002), Thanem (2004), Painter-Morland e Deslandes (2014) e Munro (2016).

Desse modo, quando destacamos uma perspectiva rizomática, evocamos integralmente a teoria da multiplicidade de Deleuze e Guattari, a fim de compreender a organização. Nossa proposição transita por uma perspectiva da organização como pensamento e construção de subjetividade, sujeita a uma dinâmica intrincada dos afetos, que podem tanto libertar, criando novos mundos, como aprisionar a subjetividade na produção operada por um inconsciente colonial-capitalístico (Rolnik, 2018).

Assim, a organização como pensamento sem imagem exprime múltiplas possibilidades de apreensão do real, essa forma múltipla de entender se desprende da compreensão tradicional de organização como contrário a desordem. Permitindo dessa forma, compreender a organização como não possuindo um lugar fixo, mas que permanece em constante movimento, preenchendo vazios e se estendendo entre as demais organizações. Assim, a divisão entre organizar e desorganizar, que compõe o sentido de organização clássica, é negada pelos conceitos de dobra e rizoma em Deleuze e Guattari (Pick, 2017), abrindo a organização para múltiplas formas de agenciamento, que mesmo formalizados em estratos estão constantemente operando por meio de linhas de fuga.

Nesse sentido, Linstead e Thanem (2007) argumentam que a organização possui um duplo sentido, a organização formal e o engajamento da vida, que pode ser compreendido ao observar os movimentos de produção no rizoma. Assim, a organização rizomática é mais do que um espaço de ordem, de formalidades e de estratificação, sendo a experimentação da multiplicidade, em que os movimentos de fuga fazem parte da organização. Contudo, utilizar o conceito de rizoma para explicar a organização, não é negar a existência de uma arborescência, mas é abrir a compreensão para o movimento microscópico existente nessa arborescência, um desejo pela vida, que luta para ser organizado como organização formal, que mesmo formalizado em algumas linhas de segmentaridade não se fecha para a potência representada pelo lado de fora e está constantemente sendo cortado por linhas de fuga.

Falar em organização rizomática é abrir o conceito de organização para essa multiplicidade, compreendendo que o combustível para suas criações, mudanças e movimento, é o desejo. A forma que a organização toma em suas estratificações pode ser percebida por seus afetos, ou seja, como ela afeta e se deixa afetar pelas forças que constituem o lado de fora. Entretanto, esse devir-organização pode ser afetado por forças que constituem os agenciamentos maquínicos da indústria, economia, informação etc., eclipsando o devir-organização-rizoma (Paes \& Borges, 2016).

O que todos esses textos sobre a relação entre as teorias organizacionais e as concepções de Deleuze e Guatarri deixam escapar é que a organização rizomática luta para não ser organizada, constitui-se como uma indisciplina, busca a dinamicidade de suas linhas. Avançar na construção teórica de uma organização rizomática é não aceitar as formas hegemônicas como verdade e a ordem moral do que são as organizações. A organização rizomática deve ser vista no sentido do que Deleuze (2018) descreve a respeito do pensamento, como a organização sem imagem, sem forma pronta, como uma organização que se produz a todo momento e que assim não se fecha para a potência.

A organização rizomática não pode ter suas ações delimitadas, ela luta para não ser fechada, porque semelhante ao rizoma que morre quando é fechado, a organização morre a cada momento que é representada em uma figura estática. Pois ela não possui um local fixo de ação, e vive o embate constante com as forças que ditam as verdades sobre as organizações e suas teorizações. O lugar da organização rizomática vai se desenhando a cada momento e movimento, sendo afetada pelas forças que constituem o lado de fora, o que não é a organização, mas que se dobra formando um lado de dentro. Apesar das forças que movimentam as linhas de segmentaridade na direção de uma formalização de suas práticas, forçando a arborescência, organizando os fluxos e desejos, existe um movimento imprevisível, de linhas de fuga que buscam constantemente romper as segmentaridades organizacionais. Por essa oposição, entende-se que os desejos não seguem passivamente a estratificação organizacional, mas seguem os caminhos da diferença, deixam-se afetar pelas múltiplas possibilidades de criação da potência. 


\section{FECHANDO, MAS NÃO ENCERRANDO ESSA DISCUSSÃO COLOCAMOS ALGUMAS CONSIDERAÇÕES}

A proposta para esse ensaio foi apresentar a perspectiva rizomática para o estudo das organizações. Uma perspectiva rizomática da organização permite a proposição conceitual de organização rizomática, que é fluida, em alguns momentos assume forma, compõe estratos e linhas de segmentaridade, que organizam e classificam os saberes. Mas, em outros momentos, rompe as linhas que a organiza e a estratifica, produzindo rupturas, seguindo os fluxos do desejo, que é o combustível para sua produção.

Contudo, as linhas de fuga na organização rizomática podem ser novamente estratificadas, produzindo novos estratos e percepções do que é a organização. O confronto é sua marca, uma vez que ela pode ser percebida por sua oposição ao sistema hierarquizante (arborescente) da organização formal. Nesse sentido, ela é constantemente afetada pelas forças do lado de fora, que agem sobre sua produção de subjetividade, por meio do processo constante de dobra do lado de fora, formando um interno que constitui uma nova memória do que é essa organização diante da potência representada pelo lado de fora.

Por essa perspectiva de olhar a organização como um rizoma, a dicotomia ordem/caos, organização/desorganização é superada, uma vez que o entendimento de limites que definem esses aspectos é o que aprisiona a máquina desejante que constitui o ser organização-rizoma. Contudo, essas prisões, características de um inconsciente colonial-capitalístico, não põem fim a sua resistência, pois ela continuará resistindo em ser limitada, hierarquizada e organizada.

Mas é dessa prisão que temos que libertar a organização rizomática. Isso porque os textos discutidos neste ensaio, que partem da relação entre organizações e a teoria de Deleuze e Guatarri, trazem as concepções teóricas desses autores para o contexto das teorias organizacionais, reduzidos a conceitos isolados. É necessário fazer o caminho inverso, levando as concepções organizacionais para o contexto teórico desses autores. Por que ainda precisa-se sustentar concepções como, por exemplo, de "organização formal", mesmo que na condição de não negação de sua existência?

É nessa condição de subversão que precisamos compreender a organização rizomática. Isso não ocasionará a perda do objeto de estudo que é a organização, mas permitirá uma compreensão muito mais integrada às condições da sociedade atual. Ainda se sustenta, no âmbito das teorias organizacionais, concepções de organização que estão há anos sendo reproduzidas, não permitindo compreender a complexidade dos processos que tensionam "organizar" atividades econômicas, sociais e de produção. É preciso entender que esses processos de "organizar", na condição atual das sociedades capitalistas, são rizomáticos. É preciso entender que, no grau zero da organização, essa sempre foi uma organização rizomática. 


\section{REFERÊNCIAS}

Ahrne, G., \& Brunsson, N. (2011). Organization outside organizations: the significance of partial organization. Organization, 18(1), 83-104.

Alcadipani, R., \& Rosa, A. R. (2011). From global management to glocal management: Latin American perspectives as a counter-dominant management epistemology. Canadian Journal of Administrative Sciences, 28(4), 453-466.

Alvesson, M., \& Deetz, S. (2006). Critical theory and postmodernism approaches to organizational studies. In S. R. Clegg, C. Hardy, T. B. Lawrence, \& W. R. Nord (Eds.), The Sage Handbook of organization studies (2 ed., pp. 255-283). London, UK: SAGE Publications.

Badiou, A. (1997). Deleuze: O clamor do Ser. Rio de Janeiro, RJ: Jorge Zahar Editor.

Ball, K. (2005). Organization, surveillance, and the body: toward a politics of resistance. Organization, 12(1), 89-108.

Barreto, R., Carrieri, A., \& Romagnoli, R. (2020). O rizoma deleuze-guattariano nas pesquisas em Estudos Organizacionais. Cadernos EBAPE.BR, 18(1), 47-60.

Bougen, P., \& Young, J. (2000). Organizing and regulating as rhizomatic lines: bank fraud and auditing. Organization, 7(3), 403-426.

Brunsson, N. (1982). The irrationality of action and action rationality: decisions, ideologies, and organizational actions. Journal of management studies, 19(1), 29-44.

Burrell, G., \& Morgan, G. (1979). Sociological paradigms and organisational analysis: Elements of the sociology of corporate life. London, UK: Routledge.

Caldas, M. (2005). Paradigmas em estudos organizacionais: uma introdução à série. Revista de Administração de Empresas, 45(1), 53-57.

Cavalcanti, M. (2016). Estudos Organizacionais e Filosofia: a contribuição de Deleuze. Revista de Administração de Empresas, 56(2), 182-191.

Cavalcanti, M., \& Alcadipani, R. (2011). Em defesa de uma crítica organizacional pós-estruturalista: recuperando o pragmatismo foucaultiano-deleuziano. Administração: Ensino e Pesquisa, 12(4), 557-582.

Chia, R. (1998). From complexity science to complex thinking: organization as simple location. Organization, 5(3), 341-369.

Chia, R. (1999). A 'rhizomic' model of organizational change and transformation: perspective from a metaphysics of change. British Journal of Management, 10(3), 209-227.

Clegg, S., Kornberger, M., \& Rhodes, C. (2005). Learning/Becoming/ Organizing. Organization, 12(2), 147-167.

Colebrook, C. (2002). Understanding Deleuze. Crows Nest, Australia: Allen \& Unwin.

Colman, F. (2010). Rhizome. In A. Parr (Ed.), The Deleuze Dictionary. Edinburg, Scotland: Edinburg University Press.

Cooper, R. (1990). Organization/Disorganization. In J. Hassard, \& D. Pyn (Ed.), The theory and philosophy of organization. London, UK: Routledge.
Cooper, R., \& Burrell, G. (1988). Modernism, postmodernism and organizational analysis: An introduction. Organizations studies, 9(1), 91-112.

Deleuze, G. (1974). Lógica do Sentido. São Paulo, SP: Perspectiva.

Deleuze, G. (2008). Conversações. São Paulo, SP: Editora 34.

Deleuze, G. (2013). Foucault. São Paulo, SP: Brasiliense.

Deleuze, G. (2018). Diferença e repetição. Lisboa, Portugal: Relógio D’Água.

Deleuze, G., \& Guattari, F. (2004). O Anti-Édipo: Capitalismo e Esquizofrenia 1. Lisboa, Portugal: Assírio \& Alvim.

Deleuze, G., \& Guattari, F. (2015). Mil Platôs: Capitalismo e Esquizofrenia. (Vol. 3). Rio de Janeiro, RJ: Editora 34.

Deleuze, G., \& Guattari, F. (2017a). Mil Platôs: Capitalismo e Esquizofrenia. (Vol. 1). Rio de Janeiro, RJ: Editora 34.

Deleuze, G., \& Guattari, F. (2017b). Mil Platôs: Capitalismo e Esquizofrenia. (Vol. 5). Rio de Janeiro, RJ: Editora 34.

Deleuze, G., \& Guattari, F. (2017c). Mil Platôs: Capitalismo e Esquizofrenia. (Vol. 4). Rio de Janeiro, RJ: Editora 34.

Dosse, F. (2010). Gilles Deleuze \& Félix Guattari: biografia cruzada. Porto Alegre, RS: Artmed.

Grisci, C. (2008). Trabalho imaterial, controle rizomático e subjetividade no novo paradigma tecnológico. Revista de Administração de Empresas, 7(1) 1-23.

Guattari, F. (1985). Revolução molecular: pulsações políticas do desejo. São Paulo, SP: Editora Brasiliense.

Guattari, F. (2006). Caosmose: um novo paradigma estético. São Paulo, SP: Editora 34.

Guattari, F., \& Rolnik, S. (1996). Micropolítica: Cartografias do desejo. Petrópolis, RJ: Vozes.

Kuronen, T., \& Huhtinen, A. (2017). Organizing conflict: the rhizome of Jihad. Journal of Management Inquiry, 26(1), 47-61.

Lawley, S. (2005). Deleuze's Rhizome and the Study of Organization: Conceptual Movement and an Open Future. Journal of Critical Postmodern Organization Science, 3(4), 36-49.

Linstead, S., \& Thanem, T. (2007). Multiplicity, virtuality and organization: the contribution of Gilles Deleuze. Organization Studies, 28(10), 1483-1501.

Livesey, G. (2010). Assemblage. In A. Parr (Ed.), The Deleuze Dictionary. Edinburg, Scotland: Edinburg University Press.

Machado, R. (2009). Deleuze, a arte e a filosofia. Rio de Janeiro, RJ: Jorge Zahar Ed.

Morgan, G. (1990). Paradigm diversity in organizational research. In J. Hassard, \& D. Pyn (Eds.), The theory and philosophy of organization. London, UK: Routledge.

Munro, R. (2001). Unmanaging/Disorganisation. Ephemera, 1(4), 395-403. 
Munro, I. (2016). Organizational resistance as a vector of deterritorialization: the case of WikiLeaks and secrecy habens. Organization, 23(4), p. 567-587.

O'Sullivan, S. (2010). Fold. In A. Parr (Ed.), The Deleuze Dictionary. Edinburg, Scotland: Edinburg University Press.

Paes, K., \& Borges, F. (2016). O sujeito lacaniano e a organização rizomática: devires-máquina-de-guerra. Farol, 3(7), 670-720.

Painter-Morland, M., \& Deslandes, G. (2014). Gender and visionary leading: rethinking 'vision' with Bergson, Deleuze e Guattari. Organization, 21(6), 844-866.

Peters, M. (2000). Pós-estruturalismo e filosofia da diferença. Belo Horizonte, MG: Autêntica.

Pick, D. (2017). Rethinking organization theory: the fold, the rhizome and the seam between organization and the literary. Organization, 24(6), 800-818.

Power, M. (1990). Modernism, postmodernism and organization. In: J. Hassard, \& D. Pyn (Eds.), The theory and philosophy of organization. London, UK: Routledge.

Reed, M. (2010). Teorização Organizacional: Um Campo Historicamente Contestado. In S. Clegg, C. Hardy, \& W. Nord (Eds.), Handbook de estudos organizacionais (Vol. 1). São Paulo, SP: Atlas.
Reedy, P. (2014). Impossible organizations: anarchism and organizational praxis. Ephemera, 14(4), 639-658.

Rolnik, S. (2018). Esferas da Insurreição: notas para uma vida não cafetinada. São Paulo, SP: N1 Edições.

Segnini, L., \& Alcadipani, R. (2014). Poder e resistência nas organizações: a propósito das contribuições de Fernando C. Prestes Motta. Revista de Administração de Empresas, 54(3), 341-347.

Sorensen, B. (2005). Immaculate defecation: Gilles Deleuze and Félix Guattari in organization theory. Sociological Review, 53(1), 120-133.

Souza, E. (2012). Pós-modernidade nos estudos organizacionais: equívocos, antagonismos e dilemas. Cadernos EBAPE.BR, 10(2), 270-283

Spinks, L. (2010). Eternal Return. In A. Parr (Ed.), The Deleuze Dictionary. Edinburg, Scotland: Edinburg University Press.

Stagoll, C. (2010). Difference. In A. Parr (Ed.), The Deleuze Dictionary. Edinburg, Scotland: Edinburg University Press.

Styhre, A. (2002). Thinking with AND: management concepts and multiplicities. Organization, 9(3), 459-475.

Thanem, T. (2004). The Body without Organs: Nonorganizational Desire in Organizational Life. Culture and Organization, 10(3), 203-217.

Eline Gomes de Oliveira Zioli

ORCID: https://orcid.org/0000-0001-6771-6714

Doutora em Administração pela Universidade Estadual de Maringá (UEM); Professora EBTT no Instituto Federal de Educação, Ciência e Tecnologia São Paulo (IFSP) - Campus Boituva. E-mail: elinezioli@ifsp.edu.br

Elisa Yoshie Ichikawa

ORCID: https://orcid.org/0000-0001-7096-7653

Doutora em Engenharia de Produção pela Universidade Federal de Santa Catarina (UFSC); Professora Associada no Departamento de Administração da Universidade Estadual de Maringá (UEM).E-mail: eyichikawa@uem.br

Luciano Mendes

ORCID: https://orcid.org/0000-0002-6159-7184

Doutor em Administração pela Universidade Federal do Rio Grande do Sul (UFRGS); Professor associado na Escola Superior de Agricultura "Luiz de Queiroz" da Universidade de São Paulo (ESALQ/USP). E-mail: mendes@usp.br 